\title{
Synthesis and characterization of poly(styrene-b-methyl methacrylate) block copolymers via ATRP and RAFT
}

\author{
Melahat GÖKTAŞ ${ }^{{ }^{*}}$
}

\begin{abstract}
Well-defined block copolymers of styrene (S) and methyl methacrylate (MMA) poly(Styrene- $b$-methyl methacrylate) [poly(S-b-MMA)] with narrow molecular weight distribution were synthesized via atom transfer radical polymerization (ATRP) and recycle additive fragmentation chain transfer (RAFT) polymerization methods using macro RAFT macroinitiator in two step. Poly-S based RAFT macroinitiator was reported from the reaction of potassium salt of ethyl xanthegonate and homo Poly-S which is synthesized by atom transfer radical polymerization of styrene using 3-chloro-1propanol initiator. Subsequently, the synthesis of poly(S-b-MMA) block copolymers were acquired via RAFT of poly-S based RAFT macroinitiator and MMA at $90{ }^{\circ} \mathrm{C}$. Poly(S-b-MMA) block copolymers were comparatively acquired in high yield and high molecular weight. The characterization of homo poly-S, RAFT macroinitiator, and poly(S-b-MMA) block copolymers were carried out by nuclear magnetic resonance spectroscopy, fourier transform infrared spectroscopy, gel permeation chromatography, thermogravimetric analysis and elemental analysis.
\end{abstract}

Keywaords: ATRP, RAFT macroinitiator, block copolymer, methyl methacrylate, styrene

\footnotetext{
${ }^{1}$ Melahat GÖKTAŞ (Orcid ID: 0000-0002-7645-8291), Yüzüncü Y1l University, Department of Science Education, Van, Turkey *Sorumlu Yazar/Corresponding Author: Melahat GÖKTAŞ, e-mail: melahat_36@hotmail.com

Bu çalışma özgün olup, 15-18 Eylül 2017 tarihinde Zonguldak’ta düzenlenen 6.Fiziksel Kimya Kongresinde sözlü bildiri olarak sunulmuştur
} 


\section{INTRODUCTION}

Polymerization techniques of polymer synthesis chemistry are widely used in the synthesis of block and graft copolymers by atom transfer radical polymerization (ATRP) (Çakmak et al., 2017), recycle additive fragmentation chain transfer polymerization (RAFT) (Kartal et al., 2014), nitroxide mediated polymerization (NMP) and ring opening polymerization (ROP) techniques. ATRP, one of the controlled radical polymerization systems, is based on the chemical equilibrium between the transferers $(\mathrm{CuI})$ and the deactivators (CuII) using redoxbased transition metal catalyst complexes (Wang, Wang et al., 2018). ATRP was reported in 1995 by Sawamato and Matyjaszewski. (Wang, Matyjaszewski et al., 1995). RAFT polymerization was reported by Rizzardo in 1998. Reversible chain transfer provides both disruption and control of the reaction. This proves the flexibility of the polymerization method of success in a wide variety of monomer and reaction conditions. (Chiefari, Chong et al., 1998). In the case of the synthesis, the RAFT and ATRP techniques represent the most recently developed controlled radical polymerization techniques for the synthesis of well known macromolecular polymers in a very wide range (Öztürk, Kaygin et al., 2016, SyangPen, Chuang et al., 2015, Conzatti, Cavalie ). et al., 2017, Öztürk, Yavuz et al., 2016, Maitrayee, Smip et al., 2018). This technique offers a significant advantage in reducing the poly dispersion of the polymer chain. The balance between deactive and active species has been taken as the basis and therefore sometimes referred to as "living" polymerization (Zaremski, Eremeev et al. 2017, Wilson, Magenau et al., 2018).

Radical occlusion mechanisms and the use of agents in the control form the basis of controlled radical polymerization techniques $(\mathrm{Wi}$, Lee et al., 2008). Ionic-living polymerization techniques are effective in polydispersity, but in recent years it has become important to develop free-radical polymerizations, due to the limited reaction conditions and applicability (Okada, Matyjaszewski et al., 2018). Controlled/"living" radical polymerization (CRP) techniques are unique in the synthesis of polymers with a narrow molecular weight distribution and a welldefined structure. This is because linearity, low polydispersity and active polymer chain ends of the monomer increase the polymer conversion and molecular weight. (Liu, Tang et al. 2015). The prediction of the structure in the synthesis of block copolymers is one of the important aspects of macromolecular chemistry. With certain combinations of block copolymers, the physical properties of the material can be strengthened and materials suitable for different purposes can be obtained (Zhang, Wang et al., 2012, Mugang, Decheng et al., 2010, Luan, Zhang et al. (Öztürk, Hazer et al., 2010, Öztürk, Göktaş and others, 2014, Mishra, Choi, et al., 2018). Block copolymers spread their use in theoretical research and technological applications due to their specific properties based on better physical advantages. The use and synthesis of block copolymers has been the subject of numerous outstanding article articles (Hazer et al, 1991, Öztürk, Göktaş et al, 2011, Öztürk, Meyvacı et al., 2017, Öztürk, Göktaş et al., 2010, Öztürk, Atalar et al, 2013, Göktaş, Öztürk et al., 2014, Spiridon, Aissou et al. 2018).

In this study, block copolymers of poly(S- $b$ MMA) were synthesized with a combination of two different controlled radical polymerization techniques in two steps. First, synthesis of the homo poly-Styrene with ATRP was performed using the 3-chloro-1-propanol initiator. Then, synthesis of the RAFT macroinitiator (RAFT agent) was performed by reaction of the homo poly-styrene with potassium ethyl xanthogenate. Secondly, block copolymers of poly(styrene- $b$ methyl methacrylate) [poly(S- $b$-MMA)] were obtained by RAFT polymerization of methyl 
methacrylate. The obtained data is explained in detail in the conclusion and discussion.

\section{MATERIAL AND METHODS}

\section{Materials}

$N, N, N^{\prime}, N^{\prime \prime}, N^{\prime \prime}$-Pentamethyldiethylenetriamine (PMDETA) Fluka product. Methanol and $N, N$ dimethylformamide (DMF) are Sigma-Aldrich products. 3-chloro-1-propanol, methyl methacrylate (MMA), styrene (S), potassium ethyl xanthogenate, copper (I) chloride $(\mathrm{CuCl})$ and THF, 2,2'-azobisisobutyronitrile (AIBN) Aldrich. Other chemicals used in the reaction were used without any purification.

\section{Synthesis of homo poly-styrene via ATRP technique}

$10 \mathrm{~mL}$ of styrene (S), $0.5 \mathrm{~g}$ of 3-chloro-1propanol, PMDETA, $\mathrm{CuCl}$ and DMF (as solvent) were placed in a $100 \mathrm{~mL}$ tube. The reaction mixture with nitrogen gas was made inert. The reaction tube was held in a thermostated oil bath at $110^{\circ} \mathrm{C}$ for 10 hours with magnetic stirrer. The tube was poured into excess methanol for precipitation of the homo poly-styrene. The homo poly-S vacuumconditioned to room temperature was dried for 72 hours. The gravimetric follow-up of the product was done.

\section{Synthesis of a new poly-S based RAFT macroinitiator}

Homo poly-styrene synthesized by ATRP at a constant amount and $3 \mathrm{~g}$ of potassium salt ethyl xanthate were reacted in THF for 48 hours and $25^{\circ} \mathrm{C}$. The reaction mixture was filtered to remove unreacted xanthate and the solvent was removed with a rotary evaporator. The resulting
poly-S based RAFT macroinitiator was precipitated in cold diethyl ether: petroleum ether $(1: 1)$ solution. It was dried at room temperature and under vacuum for four days.

\section{RAFT polymerization for poly (S-b-MMA) block copolymers}

Poly(S-b-MMA) block copolymers were synthesized using the previously prepared macro poly-S based RAFT agent and AIBN azo initiator as initiator. The second monomer block methylmethacrylate and DMF solvent were used. The reaction tube is treated with nitrogen gas. The amounts of chemicals used in the polymerization are shown in Table 1. The reaction tube was tightly sealed with a rubber septum. As reaction temperature, a thermostated oil bath was used at $90^{\circ} \mathrm{C}$. After the polymerization, methanol was used to precipitate the reaction mixture, poly(S-b-MMA) block copolymers. The polymers were dried at room temperature and under vacuum for four days. The product was weighed.

\section{RESULTS AND DISCUSSON}

Synthesis of homo poly-styrene via atom transfer radical polymerization (ATRP)

In this study, firstly synthesized homo poly-S by ATRP which one of controlled radical polymerization techniques. In accordance with the ATRP mechanism, homo Poly-S was obtained via atom transfer radical polymerization of styrene using 3-chloro-1propanol initiator and PMDETA-CuCl (as ATRP catalyst). The synthesized homo poly-S was characterization by ${ }^{1} \mathrm{H}-\mathrm{NMR}$, FT-IR. Homo poly-S synthesis mechanism is shown in Figure 1. The yield of the products was $66.22 \mathrm{wt} \%$. 


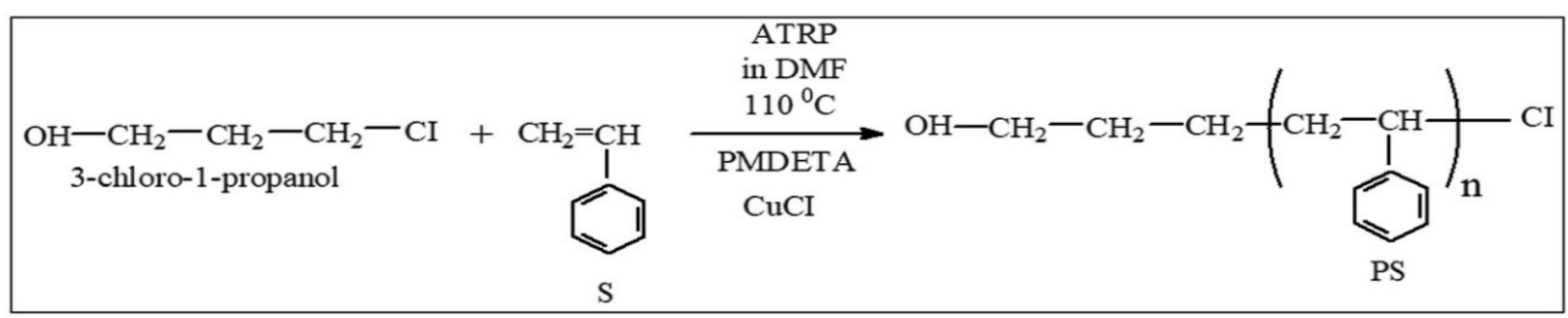

Figure 1. Synthesis route of homo poly-S via ATRP.

According to the FT-IR spectra of the homo poly-S which shown in Figure 2a. The FT-IR spectra of the poly-S shows characteristic signals at $33343 \mathrm{~cm}^{-1}$ for $-\mathrm{OH}$ groups, 2950 and 2877 $\mathrm{cm}^{-1}$ for aliphatic $-\mathrm{CH}_{2}$ and $-\mathrm{CH}$ groups. The $\mathrm{H}-$ NMR spectrum of homo poly-S in Figure $4 \mathrm{a}$ shows the characteristic signals at 6.5-7.0 ppm for phenyl protons of PS segment, 5.2-5.7 ppm for -OH protons of 3-chloro-1-propanol segment, $1.8 \mathrm{ppm}$ for $-\mathrm{CH}$ protons of PS segment, $1.5 \mathrm{ppm}$ for $-\mathrm{CH}_{2}$ protons of 3-chloro1-propanol segment, $1.4 \mathrm{ppm}$ for $-\mathrm{CH}_{2}$ protons of 3-chloro-1-propanol segment and for $-\mathrm{CH}_{2}$ protons PS segment.

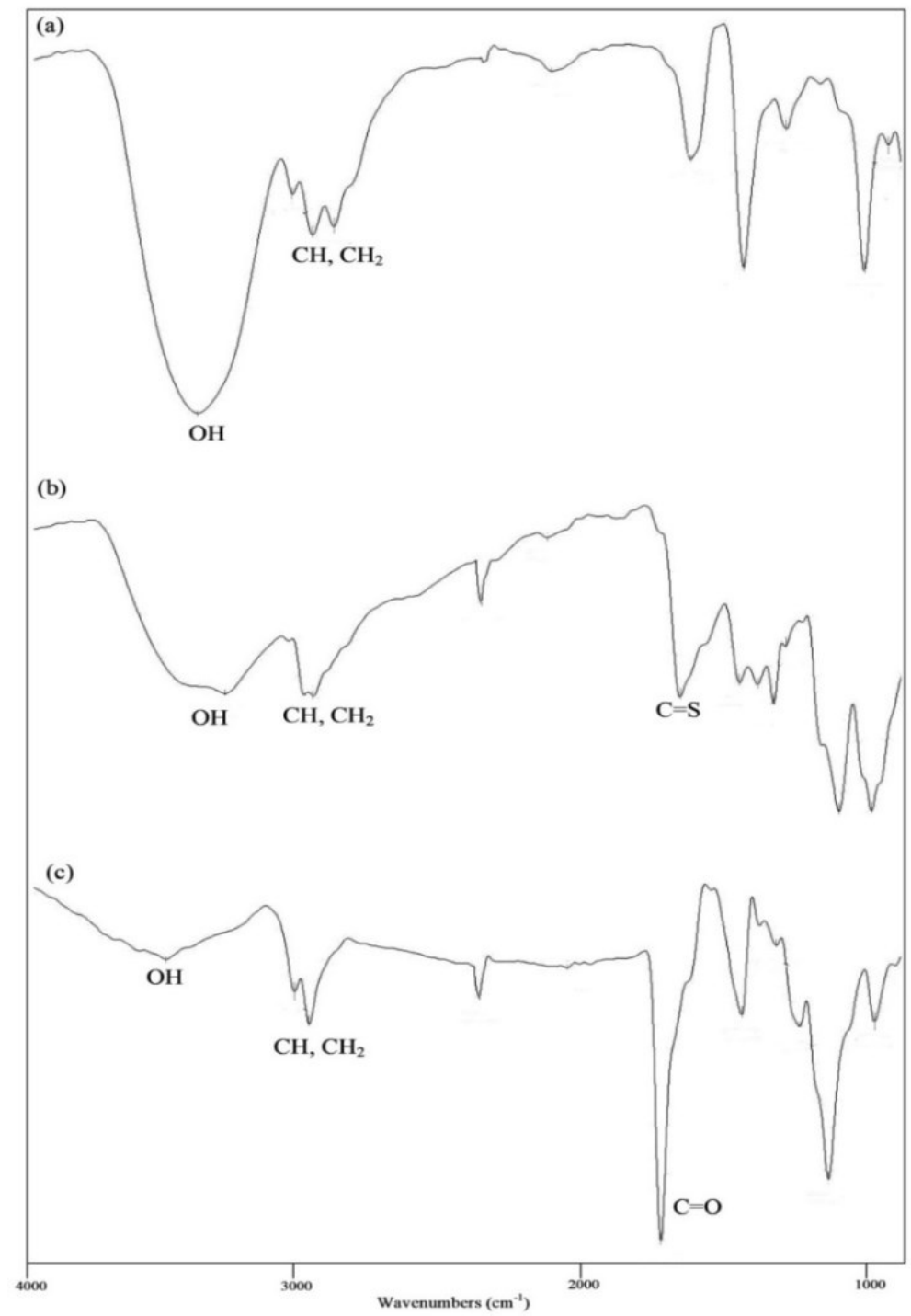

Figure 2. FTIR spectra of (a) homo poly-S, (b) poly-S based RAFT macroinitiator (c) P(S-b-MMA) block copolymers. 


\section{Synthesis of a new poly-S based RAFT macroinitiator}

In the other part of the study, poly-S based RAFT macroinitiator was obtained by the reaction of homo poly-S, synthesized by ATRP, with the potassium salt of ethyl xanthogenate. The gravimetric conversion achieved from the poly-S based RAFT macroinitiator was nearly 34.00 wt \%. RAFT macroinitiator was characterization by ${ }^{1} \mathrm{H}-\mathrm{NMR}$, FT-IR, elemental analysis. The synthesis mechanism for poly-S based RAFT macroinitiator is exhibited in Figure 3. FTIR spectra poly-S based RAFT macroinitiator in Figure $2 \mathrm{~b}$ exhibited at $3243 \mathrm{~cm}^{-}$ ${ }^{1}$ for $-\mathrm{OH}$ groups, $2938 \mathrm{~cm}^{-1}$ for aliphatic $-\mathrm{CH}_{2}$, $-\mathrm{CH}$ groups, $1662 \mathrm{~cm}^{-1}$ for $-\mathrm{C}=\mathrm{S}$ groups. The ${ }^{1} \mathrm{H}-\mathrm{NMR}$ spectrum of macro RAFT agent in Figure $4 \mathrm{~b}$ shows $1.1 \mathrm{ppm}$ for aliphatic $-\mathrm{CH}_{3}$ protons of ethyl xanthogenate segment, $2.8 \mathrm{ppm}$ for $-\mathrm{CH}_{2}$ protons of 3-chloro-1-propanol segment, $2.9 \mathrm{ppm}$ for $-\mathrm{CH}_{2}$ protons of PS segment, $3.4 \mathrm{ppm}$ for $-\mathrm{OH}$ protons of 3-chloro1-propanol segment, $4.1 \mathrm{ppm}$ for $-\mathrm{OCH}_{2}$ protons of ethyl xanthogenate segment, $4.3 \mathrm{ppm}$ for $-\mathrm{CH}$ protons of PS segment, 6.5-6.9 ppm for phenyl protons of PS segment.

The results of the elemental analysis demonstrate 70.82 wt $\% \mathrm{C}, 6.08$ wt $\% \mathrm{H}$, and $\% 7.32$ wt \% S. The results of the elemental analysis conform to theoretical values.

\section{RAFT technique for poly(S-b-MMA) block copolymers}

Blok copolymers PS- $b$-PMMA synthesis was carried out with ATRP and RAFT in two stages with controlled radical polymerization techniques. The RAFT polymerization initiated PS- $b$-PMMA block copolymer of MMA initiated by the poly-S based RAFT macroinitiator was obtained. The synthesis mechanism of the poly(S-b-MMA) block copolymer is shown in Figure 5. The effect of the reaction on the block copolymerization in the presence of the poly-Sbased RAFT macroinitiator, the amount of monomer, the duration of polymerization and the amount of macroinitiator; RAFT technique was applied. The results of the copolymerization of MMA are given in Table 1. The conversion of the monomers over time has increased from $19.86 \%$ to $97.00 \%$ by weight.

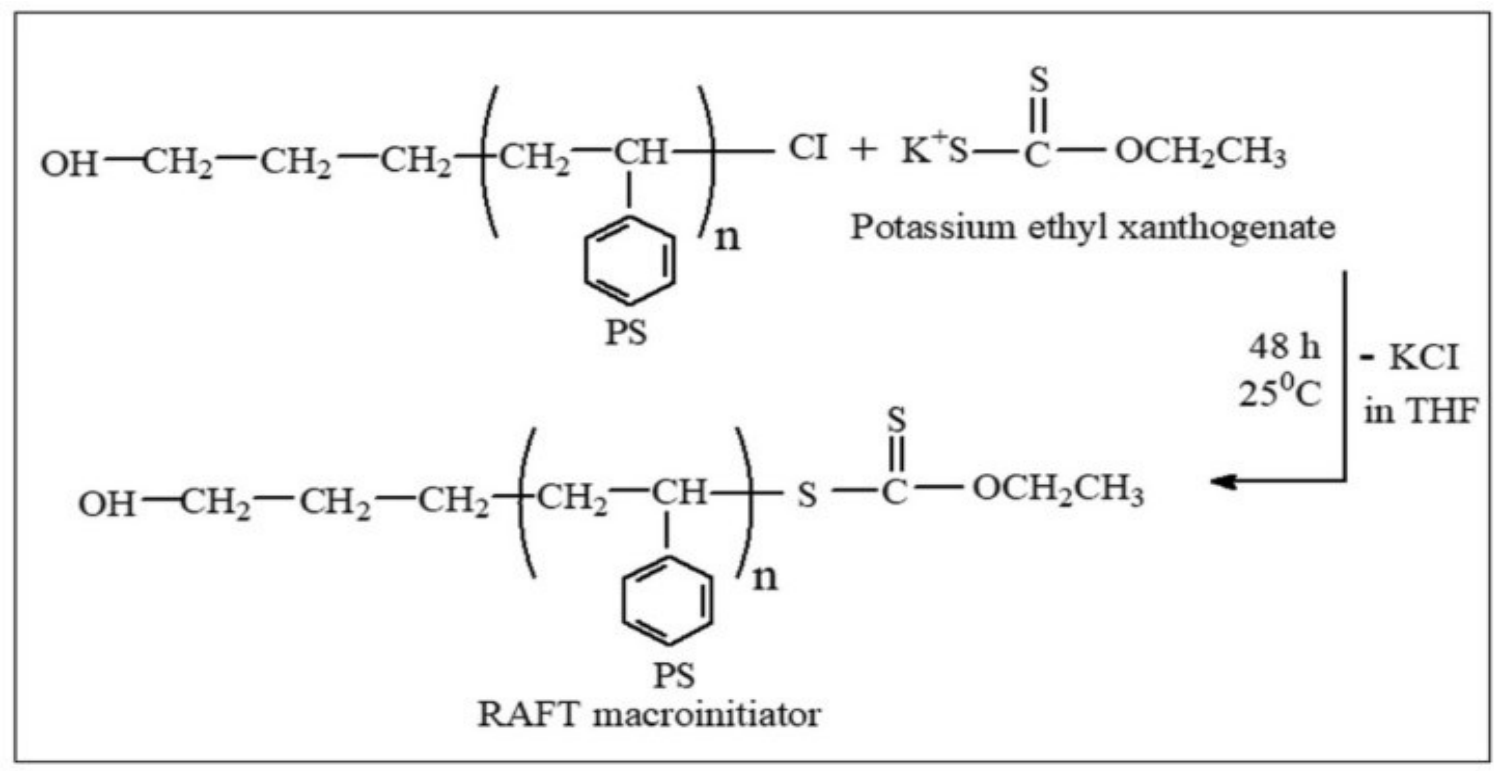

Figure 3. Synthesis route of poly-S based RAFT macroinitiator 


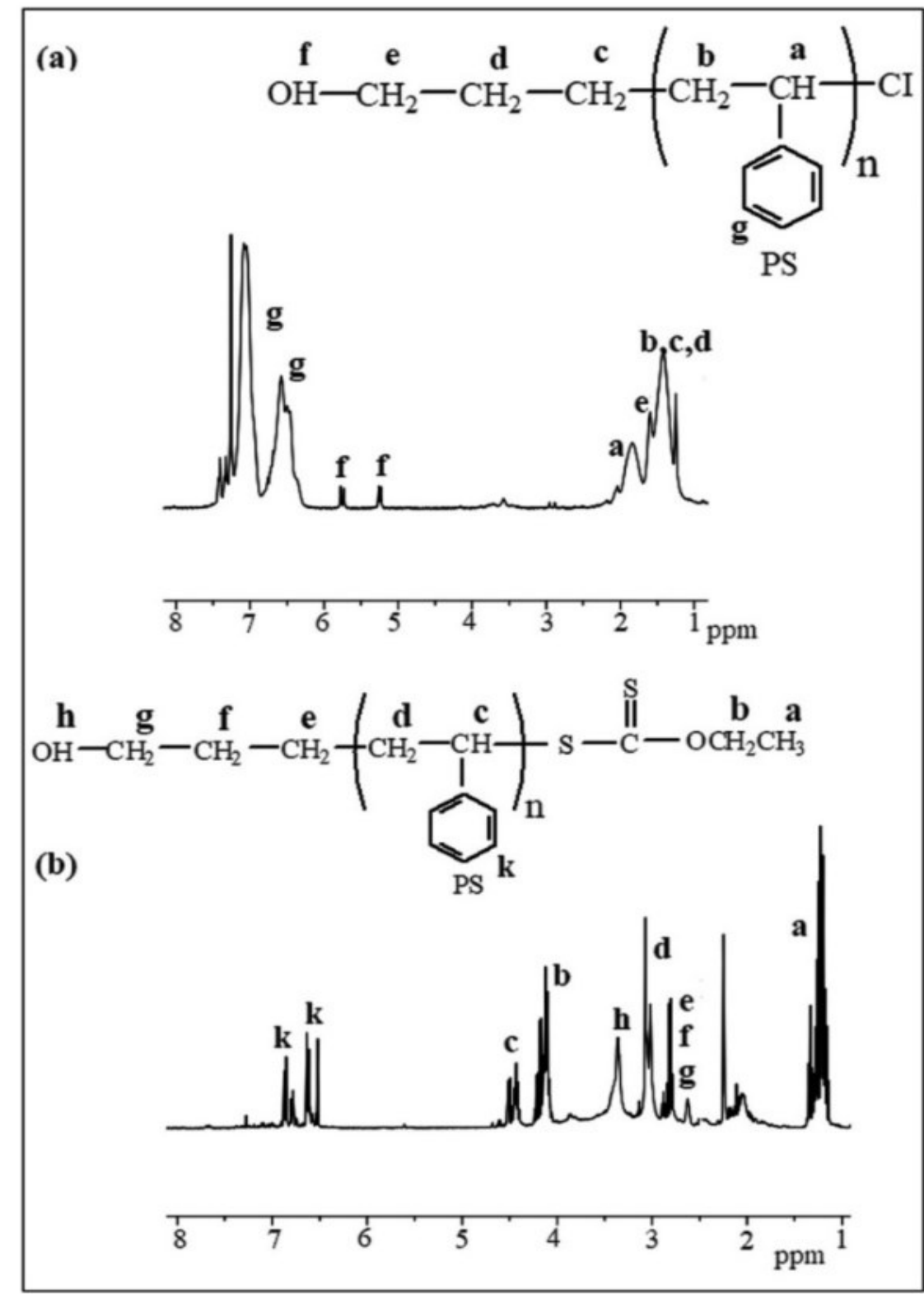

Figure 4. ${ }^{1} \mathrm{H}-\mathrm{NMR}$ spectrum of (a) homo poly-S, and (b) poly-S based RAFT macroinitiator

Table 1 The effects of polymerization time, amount of RAFT macroinitiator, and amount of the monomer on the block copolymerization. Polymer temperature $=90{ }^{\circ} \mathrm{C}, \mathrm{DMF}=3 \mathrm{ml}$

\begin{tabular}{ccccccccc}
\hline Code & $\begin{array}{c}\text { RAFT- } \\
\text { Agent }\end{array}$ & $\begin{array}{c}\text { MMA } \\
(\mathrm{g})\end{array}$ & $\begin{array}{c}\text { AIBN } \\
(\mathrm{g})\end{array}$ & $\begin{array}{c}\text { Yield } \\
(\mathrm{g})\end{array}$ & $\begin{array}{c}\text { Conversion } \\
(\%)\end{array}$ & $\begin{array}{c}\text { Time } \\
(\mathrm{min} .)\end{array}$ & Mn GPC & Mw/Mn \\
& $(\mathrm{g})$ & & & & &
\end{tabular}

(g)

\begin{tabular}{lllllllll}
\hline NA-1 & 0.075 & 1.5 & 0.0016 & 0.6700 & 49.30 & 40 & 12712 & 1.39 \\
\hline NA-2 & 0.075 & 1.5 & 0.0016 & 0.0270 & 19.86 & 100 & 26535 & 1.33 \\
\hline DA-1 & 0.050 & 2.0 & 0.0016 & 1.4900 & 82.00 & 60 & 29166 & 1.61 \\
\hline DA-2 & 0.050 & 2.5 & 0.0016 & 2.5300 & 91.00 & 60 & 32062 & 1.78 \\
\hline DA-3 & 0.050 & 3.0 & 0.0016 & 2.6500 & 97.00 & 60 & 14724 & 1.25 \\
\hline DU-2 & 0.075 & 2.0 & 0.0320 & 0.5500 & 29.11 & 80 & 14838 & 1.70 \\
\hline DU-3 & 0.100 & 2.0 & 0.0320 & 0.6900 & 36.66 & 80 & 13066 & 1.68 \\
\hline
\end{tabular}




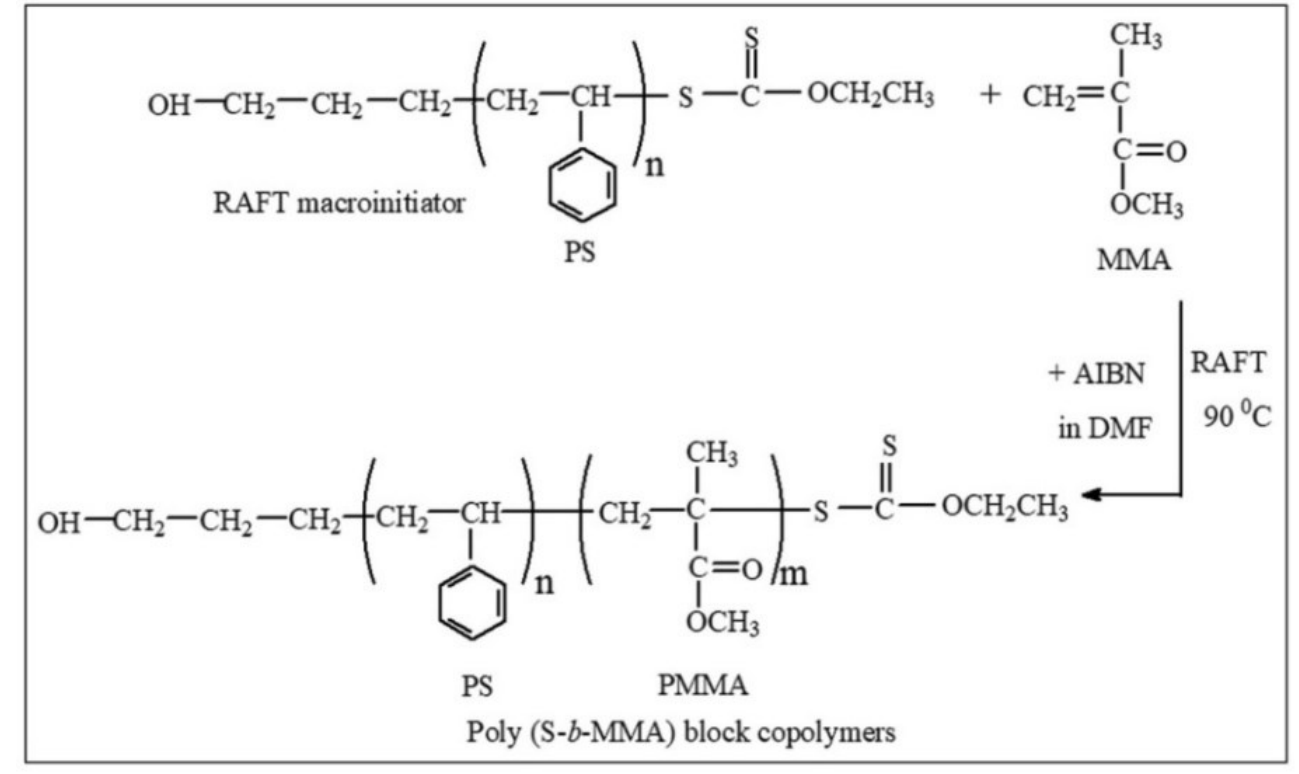

Figure 5. Reaction pathways in the synthesis of poly(S-b-MMA) block copolymers

The FTIR spectra of poly(S- $b$-MMA) block copolymer is given in Figure $2 \mathrm{c}$. The signals at $3444 \mathrm{~cm}^{-1}$ for $-\mathrm{OH}$ groups, 2996 and $2946 \mathrm{~cm}^{-1}$ for aliphatic $-\mathrm{CH}_{2}$ and $-\mathrm{CH}$ groups, $1724 \mathrm{~cm}^{-1}$ for $-\mathrm{C}=\mathrm{O}$ groups. Typical ${ }^{1} \mathrm{H}-\mathrm{NMR}$ spectra of block copolymers in Figure 6 demonstrates 0.8 ppm for aliphatic $-\mathrm{CH}_{3}$ protons of ethyl xanthogenate and $-\mathrm{CH}_{3}$ protons of PMMA, 1.0 ppm for $-\mathrm{CH}_{2}$ protons of PMMA segment, for -
$\mathrm{CH}_{2}$ protons of PS segment, for $-\mathrm{CH}_{2}$ protons of 3-chloro-1-propanol segment, $1.2 \mathrm{ppm}$ for $-\mathrm{CH}$ protons of PS segment, $1.6 \mathrm{ppm}$ for $-\mathrm{CH}_{2}$ protons of 3-chloro-1-propanol segment, 1.8 ppm for for $-\mathrm{OCH}_{2}$ protons of ethyl xanthogenate, $2.9 \mathrm{ppm}$ for $-\mathrm{OH}$ protons of 3chloro-1-propanol segment, $3.6 \mathrm{ppm}$ for $-\mathrm{OCH}_{3}$ protons of PMMA, 6.9-8.0 ppm for phenyl protons of PS segment.

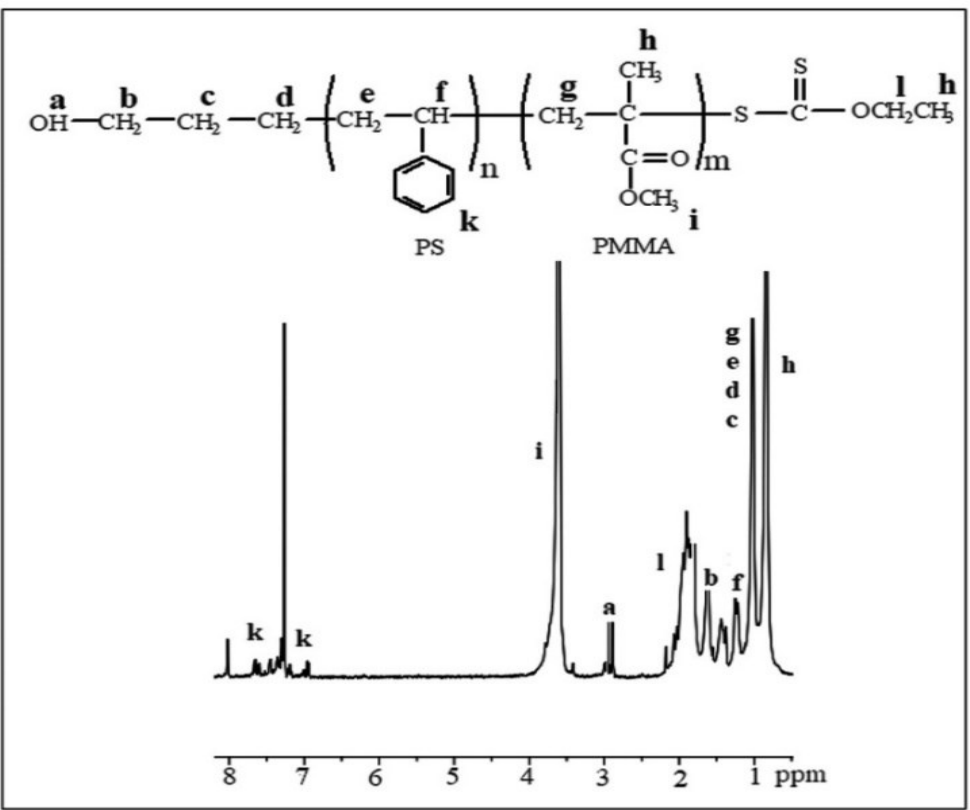

Figure 6. ${ }^{1} \mathrm{H}-\mathrm{NMR}$ spectrum of poly(S-b-MMA) block copolymers 
Methyl methacrylate polymerization was carried out by RAFT polymerization using the poly-S based RAFT macroinitiator (Table 1). The effect of the reaction time in the block copolymerization synthesis of the polymerization time is given in Table 1 (NA-1 and NA-2). Products with large molecular weights were obtained during long-term polymerization times. These results show good agreement with the work of Heidenreich and Puskas (Heidenreich, puskas et al, 2008) for RAFT polymerization. Increasing the amount of monomer provides both the yield of the copolymers and the molecular weight increase. (DA-1, DA-2 and DA-3 in Table 1). When examined, increasing the amount of RAFT macroinitiator leads to the formation of numerous active centers. As a result of this, we have produced excess radicals in the polymerization. Thus, as shown in Table 1 (DU2 and DU-3), a decrease in the molecular weights of block copolymers was similarly observed in our previous texts (Öztürk, Kaygin et al., 2016, Öztürk, Yavuz et al., 2016, Öztürk , Göktaş et al. 2010).

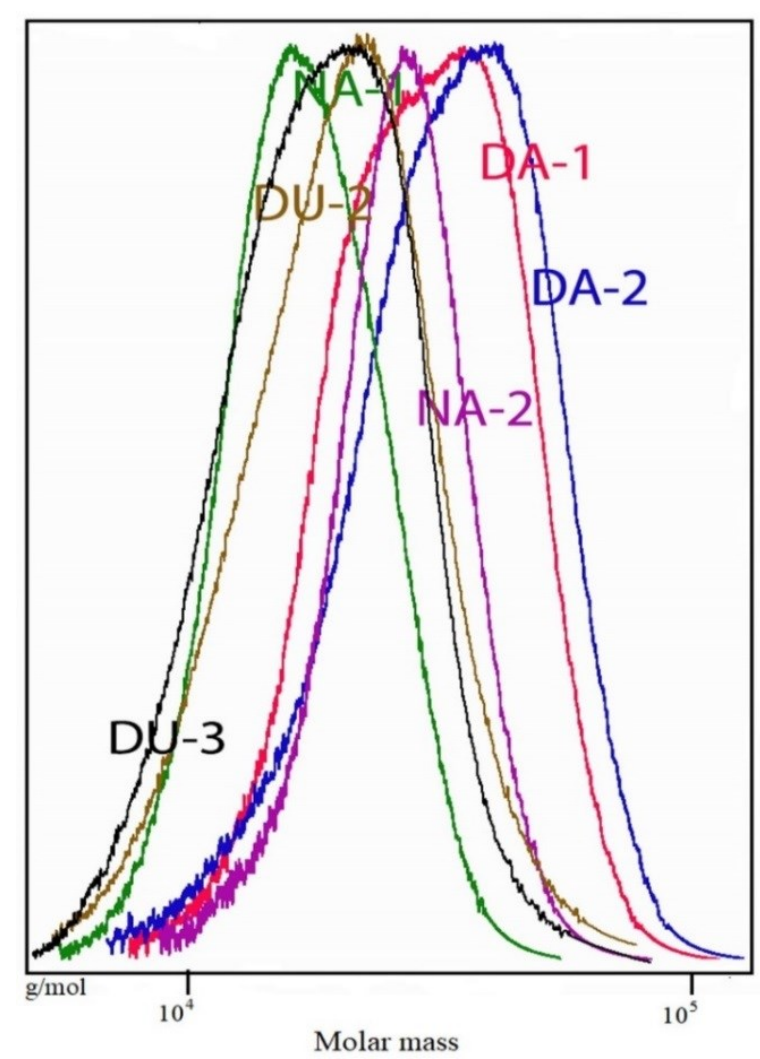

Figure 7. GPC chromatograms of NA, DA and DU series in Table 1.

The polydispersity $\mathrm{Mw} / \mathrm{Mn}$ values of the poly(S-b-MMA) block copolymers are between 1.25 and 1.78 , (Table 1). The Mw/Mn values of the block copolymers obtained as a result of the combination of the two controlled polymerization techniques have a good value.

However, it is relatively high due to the formation of numerous active centers.
GPC spectra were taken for all of the poly(S-b-MMA) block copolymers. Unimodal GPC curves of block copolymers are shown in Figure 7 (NA-1, NA-2, DA-1, DA-2 and DU-2, DU-3, in Table 1). 


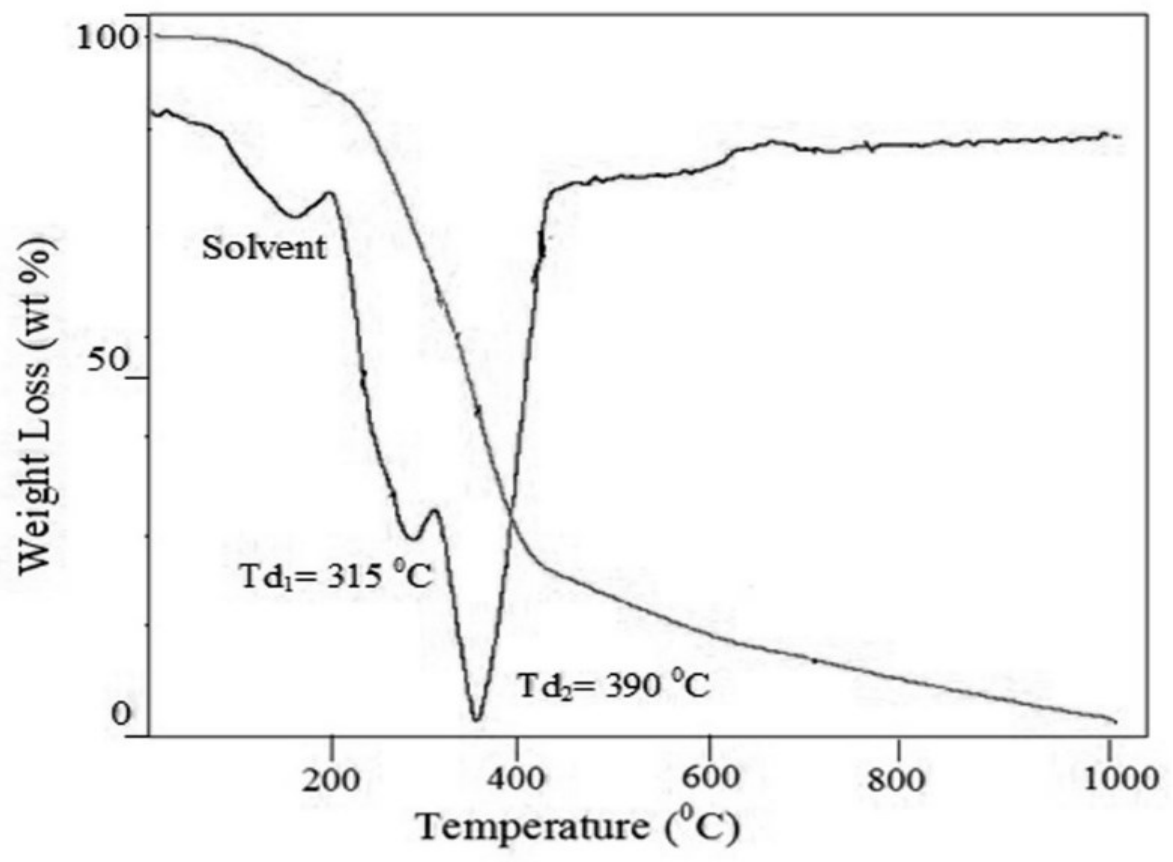

Figure 8. TGA curves of poly(S-b-MMA) block copolymers (DA-2 in Table 1).

TGA analysis was performed to determine the degradation temperatures $(\mathrm{Td})$ of the poly $(\mathrm{S}$ $b$-MMA) block copolymers. Thermal characterization of copolymers was achieved by recording their weight loss curves with temperature. TGA showed degradation properties of the block copolymer indicating continuous weight loss starting from $10{ }^{\circ} \mathrm{C}$ to $1000{ }^{\circ} \mathrm{C}$. In the case of poly(S-b-MMA) block copolymer (DA-2), PS, PMMA blocks had the separate decomposition temperatures as shown in Figure 8 [ca. $315{ }^{\circ} \mathrm{C}$, and $390{ }^{\circ} \mathrm{C}$, respectively].

\section{CONCLUSION}

In this work, poly(S-b-MMA) block copolymers were synthesized in two step by controlled radical polymerization. For this purpose, synthesized homo poly-S by atom transfer radical polymerization (ATRP) and then synthesized a novel poly-S based RAFT macroinitiator. Finally, poly-S based RAFT macroinitiator was used as initiator for RAFT polymerization one of the controlled radical polymerization methods and poly(S-b-MMA) block copolymers were obtained. The block copolymers were relatively obtained in high yield and molar weight.

With this study, Poly(S-b-MMA) block copolymers have added to literature via RAFT and ATRP polymerization techniques. The suggested process for the preparation of block copolymers is simple and efficient than conventional free radical polymerization. The composition of the block copolymers can be adjusted by changing the amount of initiator, the amount of monomer, and the polymerization time. Block copolymers synthesized by ATRP, RAFT and NMP have applied in various medical and biomedical process.

\section{ACKNOWLEDGEMENT}

This work was supported by the Yüzüncü Y1l University Scientific Research Fund (grand number: FBA-2016-5036). 


\section{REFERENCES}

Chiefari J, Chong YK, Ercole F, Krstina J, Jeffery J, Le TPT, Mayadunne RTA, Meijs GF, Moad CL, Moad E, Rizzardo E, Thang SH. 1998. "Living Free-Radical Polymerization by Reversible Addition-Fragmentation Chain Transfer: The RAFT Process" Macromolecules, 31(16): 55595562 .

Conzatti G, Cavalie S, Combes C, Torrisani J, Carrere N, Tourrette A, 2017. "PNIPAM grafted surfaces through ATRP and RAFT polymerization: Chemistry and bioadhesion." Colloids and Surfaces B: Biointerfaces, 151: 143155.

Çakmak İ, Öztürk T, Yı1dıko Ü, Yörük A, 2017.” Synthesis Of Poly[E-Caprolacton-BEpichlorohydryin-b-e-caprolactone]-gpoly(styrene) Block-Graft Copolymers via Cationic Ring Opening and Atom Transfer Radical Polymerization", Iğdır Univ. J. Inst. Sci. \& Tech. 7(3): 161-169

Göktaş M, Öztürk T, Atalar MN, Tekeş AT, Hazer B, 2014. "One-Step Synthesis of Triblock Copolymers via Simultaneous ReversibleAddition Fragmentation Chain Transfer (RAFT) and Ring-Opening Polymerization Using a Novel Difunctional Macro-RAFT Agent Based on Polyethylene Glycol." J Macromol Sci Part A, 51(11):854-863.

Hazer B, 1991. "Synthesis of styrene-tetrahydrofuran branched block copolymers." Eur Polym J, 27(9):975-978.

Heidenreich AJ, Puskas JE, 2008. "Synthesis of Arborescent (Dendritic) Polystyrenes via Controlled Inimer-Type Reversible AdditionFragmentation Chain Transfer Polymerization.” J Polym Sci Part A Polym Chem, 46(23):76217627.

Kartal B, Yildiko U, Ozturk S, Ata AC, Cakmak I, 2014. 'Study of Solution Polymerization of Styrene in the Presence of Poly(ethylene glycol)RAFT Agents Possessing Benzoyl Xanthate Derivatives', Journal of Macromolecular Science, Part A, 51: 990-98.
Liu H, Tang D, Tang R, Zhao Y, 2015. "Synthesis of multifunctional $\mathrm{ABC}$ stars with a reduction-labile arm by consecutive ROP RAFT and ATRP processes." Science China Chemistry, 58(11):1724-1733.

Luan B, Zhang BQ, Pan CY, 2006. "Synthesis and characterizations of well-defined branched polymers with $\mathrm{AB}(2)$ branches by combination of RAFT polymerization and ROP as well as ATRP." J Polym Sci Part A Polym Chem, 44(1):549-560.

Maitrayee Saikia, Somip Borphukan, Urmilla Baruah, Arvind Gautam, Prakash J. Saikia, Shashi D. Baruah, 2018. "Poly(ethylene-coBMA) via dual concurrent ATRP-RAFT and its thermokinetic study." J Therm Anal Calorim, 131(2):1517-1526.

Mishra AK, Choi C, Maiti S, Seo Y, Lee KS, Kim E, Kim JK, 2018. "Sequential synthesis of welldefined poly(vinyl acetate) blockpolystyreneand poly(vinyl alcohol)-block-polystyrene copolymers using difunctional chloroamide-xanthate iniferter" Polymer, 139: 68-75.

Mugang P, Decheng W, Junlian H, 2010. "Preparation of a Novel Coplymer of Hyperbranched poly-glyserol with Multi-arms of poly( $N$-isopropylacrylamide)." Chin J Chem, 28(4):499-503.

Okada S, Matyjaszewski K (2015) "Synthesis of BioBased poly(N-phenylitaconimide) by Atom Transfer Radical polymerization." J Polym Sci Part A Polym Chem, 53(6):822-827.

Öztürk T, Atalar MN, Göktaş M, Hazer B, 2013. "One-Step Synthesis of Block Graft Copolymers via Simultaneous Reversible-Addition Fragmentation Chain Transfer and Ring-Opening Polymerization Using a Novel Macroinitiator." J Polym Sci Part A Polym Chem, 51(12):26512659. 
Öztürk T, Hazer B, 2010. "Synthesis and characterization of a Novel Macromonomer Initiator for Reversible Addition Fragmentation Chain Transfer (RAFT). Evaluation of the polymerization Kinetics and Gelation Behaviors. J Macromol Sci Part A Pure and Appl Chem, 47(3):265-272.

Öztürk T, Göktaş M, Hazer B, 2011. "Synthesis and Characterization of Poly(methyl methacrylateblock-ethylene glycol-block-methyl methacrylate) Block Copolymers by Reversible AdditionFragmentation Chain Transfer Polymerization.” J Macromol Sci Part A, 48(1):65-72.

Öztürk T, Kayğın O, Göktaş M, Hazer B, 2016. "Synthesis and Characterization of Graft Copolymers Based on Polyepichlorohydrin via Reversible Addition-Fragmentation Chain Transfer Polymerization." Journal of Macromolecular Science, 53(6):362-367.

Öztürk T, Meyvac1 E, 2017. "Synthesis and Characterization Poly(E-Caprolactone-b- Ethylene Glycol-b-E-Caprolactone) Block Copolymers via "Click" Chemistry and Ring Opening Polymerization." J Macromol Sci Part A, 54(9):575-581.

Öztürk T, Göktaş M, Savaş B, Iş1klar M, Atalar MN, Hazer B, 2014. "Synthesis and characterization of poly(vinylchloride-graft-2-vinylpyridine) graft copolymersusing a novel macroinitiator by reversible addition-fragmentation chain transfer polymerization." e-Polymers, 14(1):27-34.

Öztürk T, Yavuz M, Göktaş M, Hazer B, 2016. "One-step synthesis of triarm block copolymers by simultaneous atom transfer radical and ringopening polymerization." Polymer Bulletin, 73(6):1497-1513.

Öztürk T, Göktaş M, Hazer B, 2010. “One-Step Synthesis of Triarm Block Copolymers via Simultaneous Reversible-Addition Fragmentation Chain Transfer and Ring-Opening Polymerization." Journal of Applied Polymer Science, 117(3):1638-1645.
Syang-Peng R, Chuang YY, Way TF, 2015. "Preparation of thermo-responsive star copolymers via ATRP and its use in drug release application." Colloid and Polymer Science, 293(2):493-503.

Spiridon MC, Aissou K, Mumtaz M, Brochon C, Cloutet E, Fleury G, Hadziioannou G, 2018. "Surface relief gratings formed by microphaseseparated disperse red 1 acrylate-containing diblock copolymers." Polymer, 137: 378-384.

Wang Z, Wang Z, Pan X, Fu L, Lathwal S, Olszewski M, Yan J, Enciso AE, Wang Z, Xia H, Matyjaszewski K, 2018. "Ultrasonication-Induced Aqueous Atom Transfer Radical Polymerization" ACS Macro Letters, 7(3):275-280.

Wang JS, Matyjaszewski K, 1995. "Controlled/"Living" Radical Polymerization. Halogen Atom Transfer Radical Polymerization Promoted by a $\mathrm{Cu}(\mathrm{I}) / \mathrm{Cu}(11)$ Redox Process." Macromolecules, 28(23):7901-7910.

Wilson OR, Magenau AJD, 2018. "Oxygen Tolerant and Room Temperature RAFT through Alkylborane Initiation" ACS Macro Letters, 7(3): 370-375.

Wi Y, Lee K, Hyung B, Choe, S, 2008. "Soap-free emulsion polymerization of styrene using poly (methacrylic acid) macro-RAFT agent." Polymer, 49(26):5626-5635.

Zaremski M, Eremeev I, Garina E, Borisova O, Korolev B, 2017. "Controlled synthesis of random, block-random and gradient styrene methyl methacrylate and acrylonitrile Terpolymers via Nitroxide-mediated free radical polymerization." Journal of polymer research, 24(9): 151.

Zhang WA, Wang SH, Li XH, Yuan JY, Wang SL, 2012. "Organic/inorganic hybrid star-shaped block copolymers of poly(L- lactide) and poly $(\mathrm{N}$ isopropylacrylamide) with a polyhedral oligomeric silsesquioxane core: Synthesis and self-assembly." European polymer Journal, 48(4):720-729. 